\title{
Análise da arborização viária e infraestrutura urbana na Rua Joubert de Carvalho, Maringá/PR
}

\author{
Analysis of street tree and urban infrastructure in Joubert de Carvalho Street, Maringá - Parana, Brazil \\ Ricardo Massulo Albertin', Bruno Luiz Domingos De Angelis², Frederico Fonseca Silva², \\ Fábio Henrique Soares Angeoletto ${ }^{4}$, Nicéia Rêgo ${ }^{5}$. Fernando Santil ${ }^{6}$ \\ ' Doutorando em Geografia, Universidade Estadual de Maringá, PR,Brasil \\ 2,5,6 Universidade Estadual de Maringá, PR, Brasil
}

\section{Resumo}

A arborização de acompanhamento viário é um dos aspectos da ambiência urbana, cuja importância está relacionada à função química, física, paisagística, psicológica, ecológica, pedológica, hidrológica, atmosférica e acústica. Porém, muitas vezes, as árvores dividem espaço com a infraestrutura urbana, o que pode causar conflitos. A compatibilização da arborização com a infraestrutura urbana (postes, bocas de lobo, lixeiras, calçadas) é uma tarefa que exige estudo, planejamento e gestão. Nesse contexto, o objetivo é analisar a arborização viária e sua relação com a infraestrutura urbana na Rua Joubert de Carvalho, na cidade de Maringá, Paraná. Os procedimentos metodológicos compreenderam duas etapas: caracterização do local e levantamento qualiquantitativo. Os resultados permitiram concluir que na área pesquisada existem 116 indivíduos arbóreos, dos quais 44\% são da espécie Sibipiruna (Poincianella pluviosa var. peltophoroides (Benth.) L. P. Queiroz) e 19\% da espécie Jacarandá (Jacaranda mimosifolia D. Don). Foram identificados 13 espaços ausentes de árvores. Concluiu-se que $66 \%$ das árvores não causam conflitos com a infraestrutura urbana. Entretanto, os maiores índices de conflitos são com postes (6\%), edificações (8\%) e fiação aérea (11\%).

Palavras-chave: Planejamento urbano, Ambiência, Arborização urbana, Edificação.

\begin{abstract}
The urban forestry on street is one aspect of urban ambience, whose importance is related to the chemical, physical, landscape, psychological, ecological, pedological, hydrological, atmospheric and acoustic funsction. But, often, the urban trees share space with urban infrastructure and can cause conflicts. The compatibility of afforestation with urban infrastructure (poles, inlets, trash cans, sidewalks) is a task that requires research, planning and management. In this context, we analyze the street tree and its relation to urban infrastructure in Joubert de Carvalho Street, in the city of Maringá, state of Paraná, South of Brazil. The methodological procedures comprised two phases: site characterization and qualyquantitative survey. The results showed that in the studied area there are 116 tree species, which $44 \%$ are species Sibipiruna (pluviosa Poincianella var. Peltophoroides (Benth) LP Queiroz) and 19\% of Jacaranda (Jacaranda mimosifolia D. Don) species. 13 missing spaces of trees were identified. It was concluded that $66.00 \%$ of the trees do not cause conflicts with urban infrastructure. However, the highest levels of conflict are poles with (6.0\%), buildings (8.0\%) and overhead lines (11.0\%).
\end{abstract}

Keywords: Urban planning, Ambience, Urban forestry, Building. 


\section{INTRODUÇÃO}

O processo de urbanização, intensificado a partir da segunda metade da década de 1950 no Brasil, passou a significar alteração no modo de vida das pessoas e na apropriação do espaço.

O espaço urbano foi concebido através da "predominância da cidade sobre o campo" (ROLNIK, 2010, p.12). "Periferias, subúrbios, distritos industriais, estradas e vias expressas recobrem e absorvem zonas agrícolas num movimento incessante de urbanização" (ROLNIK, 2010, p.12). É um processo que devora o espaço, transformando em urbano toda a sociedade.

O processo de urbanização resulta em impactos ambientais positivos e negativos. Uma das formas de minimizar e compensar os impactos negativos é o desenvolvimento da ambiência urbana, vinculados, entre outros aspectos, a implementação de plano diretor de arborização urbana e projetos de arborização de acompanhamento viário, que atendam a qualidade de vida das populações.

Segundo a definição de Barros (2010), as cidades são estruturas que se configuram conforme as características ambientais da área e, contemporaneamente, que procuram satisfazer as necessidades de seus habitantes. Esperam-se deste meio, cuja vida social e os processos tecnológicos são intensos, condições que permitam o desenvolvimento das atividades humanas em consonância com a natureza.

Nesta acepção, a árvore urbana passa de uma função meramente estética, considerada um elemento de adorno, para uma infinidade de funções e benefícios que a torna um importante componente da infraestrutura urbana. A arborização ameniza os impactos negativos do entorno urbano e é capaz de transformar ambientes hostis em ambientes hospitaleiros para os usuários (MASCARÓ, 1994). A importância e as funções da vegetação urbana estão relacionadas, dentro outros fatores, à paisagem, ao ambiente, onde atua nos microclimas urbanos, e contribui para melhorar a ambiência urbana e a percepção das pessoas (MASCARÓ, 2002).

O desenvolvimento de uma espécie arbórea faz transpor os níveis subsolo, solo e aéreo. Nesses três níveis também estão presentes os equipamentos que compõem o sistema viário urbano, tais como redes de energia elétrica, telefônica, abastecimento de água, coleta de esgoto, calçadas, postes de iluminação, sinais de trânsito e edificações (BARROS, 2010). Considera-se ainda que outros parâmetros como a geometria, as dimensões das caixas de rolamento, dos passeios públicos, da área permeável disponível e dos recuos de jardim são fundamentais para o desenvolvimento a e avaliação do comportamento das espécies vegetais (MASCARÓ, 2002).

A compatibilização da arborização urbana com a infraestrutura urbana e, respectivamente, as estruturas e equipamentos de utilidade pública são tarefas que exigem estudo e planejamento. Razão pela qual se recomenda que a arborização seja objeto de um planejamento prévio, de modo que a torne compatível com a área urbana já consolidada (COPEL, 2008). A instalação de árvores nas cidades não pode ser realizada de forma amadorística e aleatória. Nesse processo, muitas vezes, não são contempladas as melhores regras no que se refere à seleção das espécies, às condições de plantio e aos tratamentos inicias (CARVALHO, 2009).

Nesse sentido, o presente trabalho teve por objetivo diagnosticar e analisar de forma qualiquantitativa a arborização viária e sua relação com a infraestrutura urbana (sistema de distribuição de energia elétrica, bocas de lobo e calçadas) na Rua Joubert de Carvalho, localizado na cidade de Maringá, Estado do Paraná, Sul do Brasil.

\section{PROCEDIMENTOS METODOLÓGICOS}

\section{I LOCAL DE ESTUDO}

O presente estudo foi realizado na cidade de Maringá, Estado do Paraná, Sul do Brasil (Figura 1). Possui área territorial de $487,052 \mathrm{~km}^{2}$, população de 357.077 hab. e densidade demográfica de $732,12 \mathrm{hab} / \mathrm{km}^{2}$ (IBGE, 2013).

Maringá está associada diretamente a um grande empreendimento agrícola e imobiliário, que é decorrente da marcha pioneiro rumo ao Norte do Paraná. A Companhia Melhoramentos Norte do Paraná (CMNP) promoveu o planejamento territorial da região com a instalação de uma rede de cidades. A cidade foi projetada pelo engenheiro Jorge de Marcedo Vieira, que imprimiu ao seu desenho o caráter do tipo Garden city (REGO, 2001).

O objeto de estudo é a Rua Joubert de Carvalho, que se localiza na Zona 1, área central da 


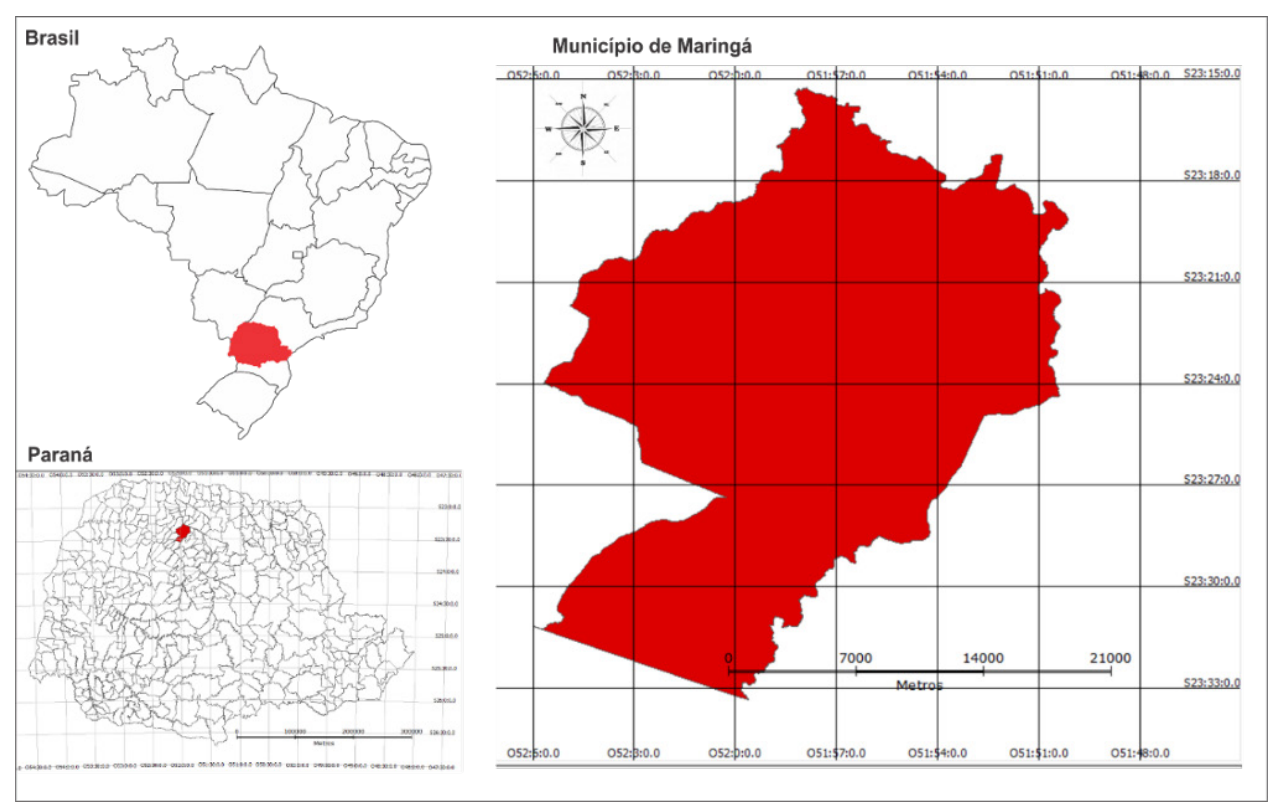

Figura 01 - Localização do município de Maringá

Fonte: Adaptado de ITCG (2013)

cidade de Maringá (Figura 2). A escolha deste objeto foi motivada por dois fatos: primeiramente pelo logradouro fazer parte do traçado inicial da cidade, projetado pelo eng. Jorge de Macedo Vieira; secundariamente por ter grande representatividade no que se refere à arborização de acompanhamento viário, pois, segundo registrado pelo jornal "O Diário do Norte do Paraná", foi no cruzamento deste logradouro com a Av. Duque de Caxias, em frente ao escritório da CMNP, que Geraldo Pinheiro Fonseca planou a primeira árvore do perímetro urbano da cidade, no final da década de 1940 (HISTÓRIA DE MARINGÁ, 2010).

Atualmente a Rua Joubert de Carvalho (Figura 2) é caracterizada como Zona de Comércio Central (ZCC). Possui 1.015m de comprimento, com duas faixas de rolagem, sentido único e uma faixa

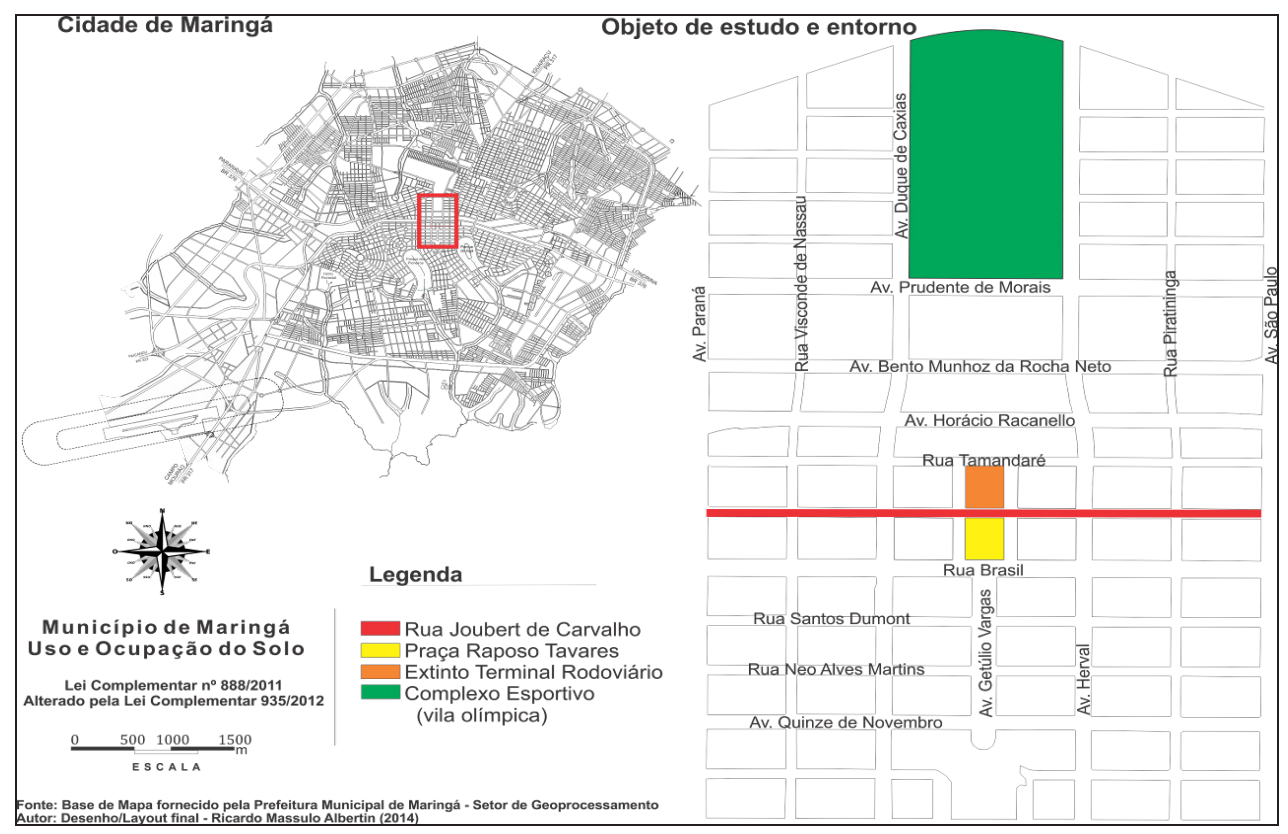

Figura 02 - Localização da área de estudo (Rua Joubert de Carvalho)

Fonte: Adaptado de Prefeitura Municial de Maringá (2014) 
destinada para estacionamento, que será suprimida com a implantação do sistema binário, tornando a via com três faixas de rolagem (MARINGÁ, 2011).

\subsection{LeVANTAMENTO QUALIQUANTITATIVO}

O procedimento metodológico adotado para o levantamento e coleta dos dados foi o censo total, ou seja, todos os indivíduos arbóreos foram amostrados.

Em relação à infraestrutura urbana, este é conceituado como um sistema técnico de equipamentos e serviços necessários ao desenvolvimento das funções urbanas, sob os aspectos sociais, econômicos e institucionais, presentes no nível aéreo, nível da superfície do terreno e nível subterrâneo. Seu conjunto é subdividido em sistema viário, sistema de drenagem pluvial, sistema de abastecimento de água, sistema de esgotos sanitários, sistema energético e sistema de comunicações. Alguns equipamentos e estruturas contidos nestes sistemas, tais como bocas de lobo, postes, redes de distribuição de energia e comunicações, pavimentação, placas de trânsito, calçadas, meios-fios, poços de visitas, ligações prediais e garagens influenciam na localização e escolha da espécie a ser plantada (ZMITROWICZ; DE ANGELIS, 1997). Para o presente estudo foram localizadas as estruturas e os equipamentos que compõem os sistemas de infraestrutura urbana, sendo postes, lixeiras, calçadas e bocas de lobo.

Os procedimentos de coleta de dados seguirão questionário adaptado de Sampaio (2006), descrito a seguir:

a) Quanto à localização e identificação dos indivíduos arbóreos:

- Localização: todos os indivíduos arbóreos e a infraestrutura urbana (postes e bocas de lobo) foram localizados por meio da obtenção das coordenadas UTM, obtidas com GPS GarminEtrex ${ }^{\circledR} 10$.

- Identificação dos indivíduos arbóreos: utilizou-se a metodologia usual taxonômica e consulta bibliográfica baseada em SOUZA; LORENZI (2008). O sistema de classificação foi baseado em APG II (2003).

b) Status (S) - Para identificar o tipo de registro, separou-se nas seguintes categorias:

- Adulta-árvore viva com mais de 3 metros de altura;

- Jovem - árvore viva com até 3 metros de altura;

- Morta-árvore morta ou que aparenta estar morta;

- Cortada - toco de uma árvore que existia no local, ou vestígios evidentes da existência anterior no local dessa árvore;

- Ausente - área livre vazia de vestígios da existência de árvore que poderia ter existido no local.

c) Quanto ao Sistema Radicular: Foram feitas as seguintes denominações para classificar o sistema radicular:

- Sem Afloramento - Raiz totalmente de forma subterrânea;

- Com Afloramento dentro da Área Livre - Raiz de forma superficial somente dentro da área de crescimento da árvore imposta pelo calçamento;

- Afetando Calçada ou via - Raiz de forma superficial, ultrapassando a área de crescimento e provocando rachaduras nas calçadas;

- Afetando rede Subterrânea de Forma Evidente - Raiz que evidentemente causou danos à rede subterrânea de água e esgoto.

d) Quanto às podas Anteriores (Poda) - Verificação da presença de poda executada na árvore. A verificação se dividiu em quatro itens:

- Poda elétrica - Quando é visível que foi retirado galhos da árvore devido a rede elétrica;

- Poda edificação - Quando é visível que foi executada a retirada de galhos devido ao conflito com as edificações.

- Sem poda anterior - Quando não está evidente que ocorreu retirada de galhos.

- Com poda drástica - Quando a poda executada desequilibra a árvore, ou quando galhos em excesso foram retirados, provocando uma injúria mecânica séria na árvore. 
e) Quanto à rede elétrica:

- Rede compacta;

- Rede elétrica simples;

- Sem rede elétrica:

- Apenas baixa tensão;

- Sem rede elétrica, porém com poste devido a ligação predial;

- Rede elétrica de alta tensão, mas não compacta.

f) Quanto aos conflitos (copa, tronco e raiz):

- Conflito com edificação;

- Conflito postes;

- Conflito com bocas de lobo;

- Conflito com pedestres;

- Conflito com veículos;

- Não causa conflito;

- Conflito com fiação.

\section{RESULTADOS E DISCUSSÕES}

O traçado da cidade de Maringá foi projetado pelo urbanista Jorge de Macedo Vieira, e sua arborização ficou a cargo do Dr. Luiz Teixeira Mendes, contratado pela Companhia Melhoramentos do Paraná (CMNP) para esse fim. Teixeira Mendes, engenheiro agrônomo aposentado, conhecedor de botânica e silvicultura, adequou para cada avenida e rua um tipo de essência, de acordo com a largura das mesmas e o porte da espécie.

Até o ano de 1958, a atual Rua Joubert de Carvalho ${ }^{1}$ era denominada Rua Bandeirantes. A mudança de nomenclatura ocorreu por meio da Lei Municipal ${ }^{\circ} 110 / 1958$, que "denomina a Rua Joubert de Carvalho a atual Rua Bandeirantes" (MARINGÁ, 1958).

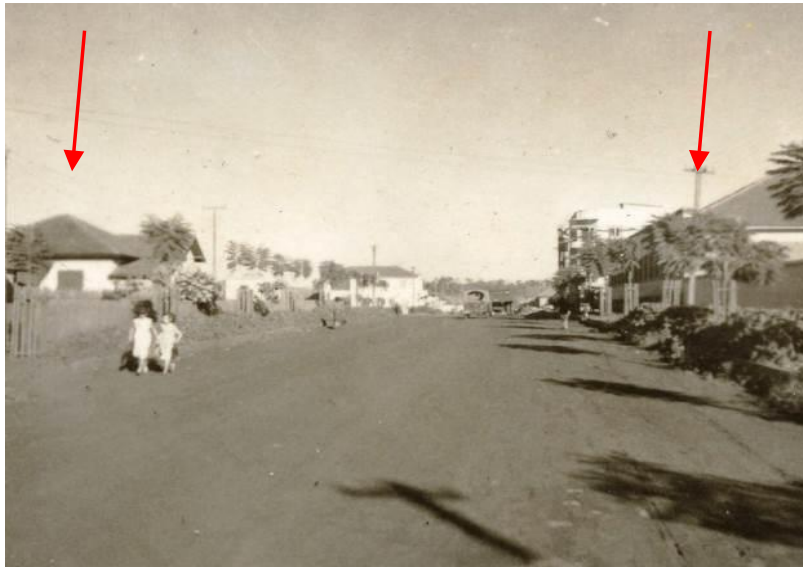

Figura 3 - Vista da Rua Bandeirantes e presença de arborização viária (início da década de 1950) Fonte: Museu bacia do Paraná (UEM)

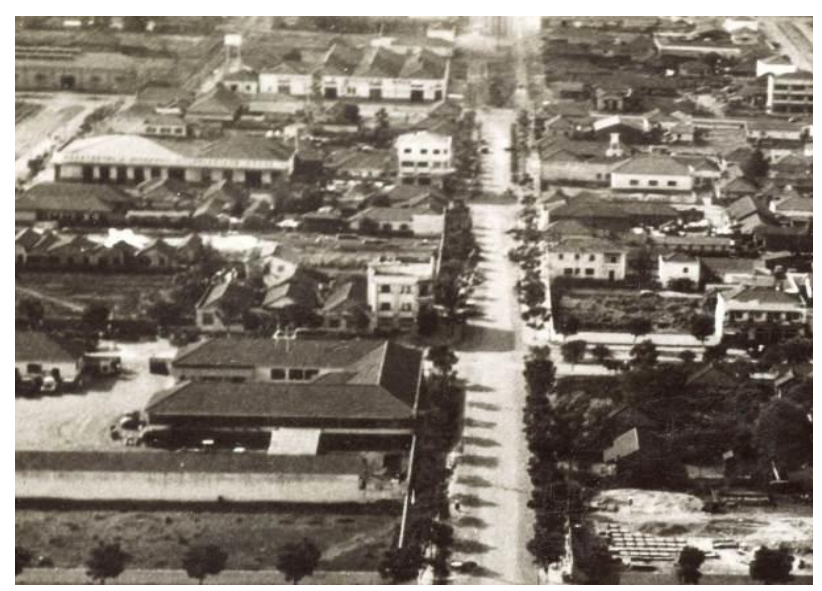

Figura 4 - Vista da Rua Bandeirantes e presença de arborização viária (final da década de 1950)

Fonte: Museu bacia do Paraná (UEM)

O plantio da arborização de acompanhamento viário na Rua Joubert de Carvalho provavelmente ocorreu logo após a execução da abertura da via, antes mesmo da pavimentação, pois há registros fotográficos da presença de árvores no início da década de 1950 (Figura 3 e 4) e pós década de 1950 (Figura 5 e 6). As espécies plantadas foram de Jacarandá (Jacaranda mimosifolia D. Don).

1 Joubert de Carvalho (1900-1977) nasceu em Uberaba (MG) foi médico e compositor de canções, dentre elas "Maringá", que deu origem ao nome da cidade do Estado do Paraná. 


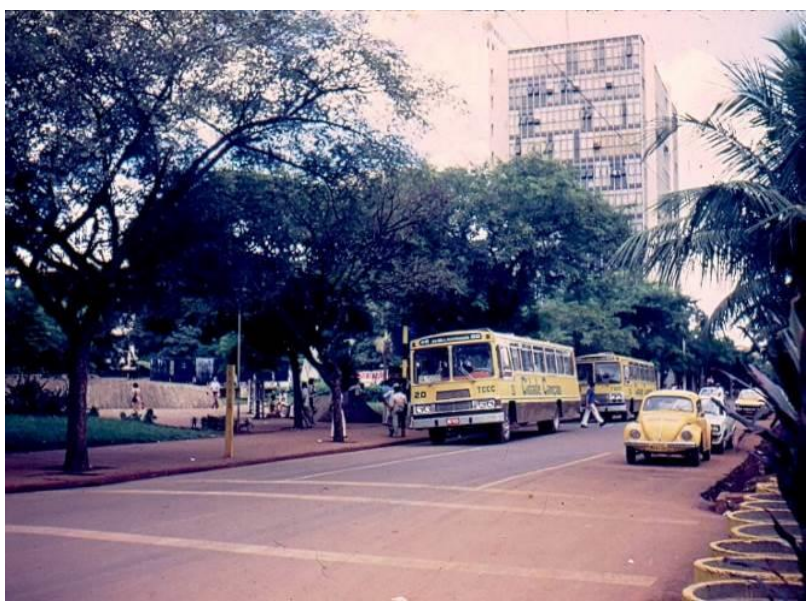

Figura 5 - Vista da Rua Joubert de Carvalho, esquina com a Travessa Mesquita, da década de 1980 Fonte: Museu bacia do Paraná (UEM)

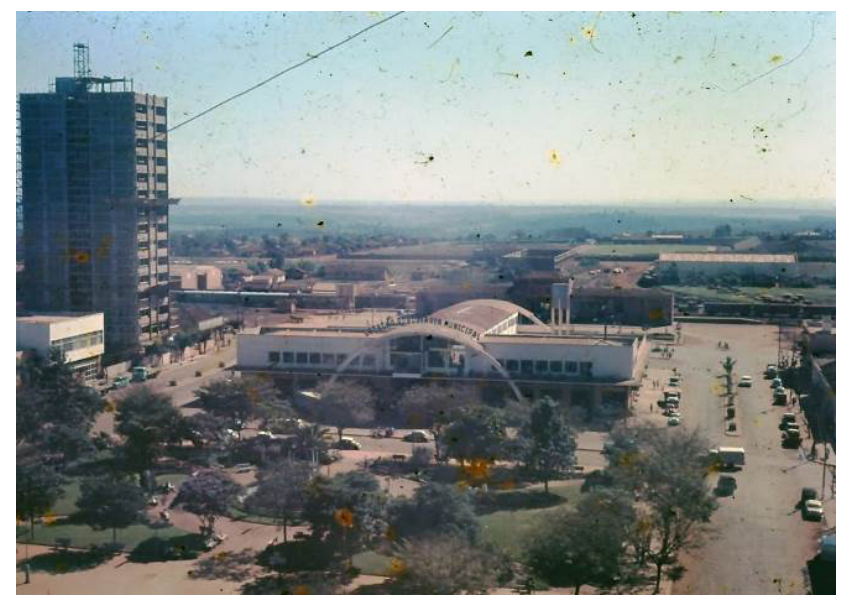

Figura 6 - Vista da antiga Estação Rodoviária de Maringá e arborização viária no entorno - década de 1960

Fonte: Museu bacia do Paraná (UEM)

Tabela 1 - Ocorrência de indivíduos arbóreos na Rua Joubert de Carvalho

\begin{tabular}{|c|c|c|c|c|c|}
\hline $\begin{array}{l}\text { Nome } \\
\text { popular }\end{array}$ & Nome científico & Família & Origem & $\mathbf{N}^{\mathbf{o}}$ & Percentual \\
\hline Sibipiruna & $\begin{array}{l}\text { Poincianella pluviosa var. peltophoroides } \\
\text { (Benth.) L. P. Queiroz }\end{array}$ & Fabaceae & Nativa & 51 & $44 \%$ \\
\hline Jacarandá & Jacaranda mimosifolia D. Don & Bignoniaceae & Nativa & 22 & $19 \%$ \\
\hline $\begin{array}{l}\text { Alecrim de } \\
\text { Campinas }\end{array}$ & Holocalyx balansae Micheli & Fabaceae & Nativa & 4 & $3 \%$ \\
\hline Mamão & Caric apapaya L. & Caricaceae & Nativa & 1 & $1 \%$ \\
\hline $\begin{array}{l}\text { Aroeira } \\
\text { Pimenta }\end{array}$ & Schinus terebinthifolius Raddi & Anacardiaceae & Nativa & 1 & $1 \%$ \\
\hline Tipuana & Tipuana tipu (Benth).Kuntze & Fabaceae & Nativa & 6 & $5 \%$ \\
\hline Oiti & Licania tomentosa (Benth.) Frirsch & Chrysobalanaceae & Nativa & 8 & $7 \%$ \\
\hline $\begin{array}{l}\text { Palmeira } \\
\text { Imperial }\end{array}$ & Roystonea oleracea (Jacq.) O. F. Cook & Arecaceae & Nativa & 2 & $2 \%$ \\
\hline Côco & Cocos nucifera L. & Arecaceae & Nativa & 5 & $4 \%$ \\
\hline Aroeira Salsa & Schinus molle L. & Anacardiaceae & Nativa & 1 & $1 \%$ \\
\hline Ipê Amarelo & Pouteriagrandiflora (Wall) Baehni & Bignoniaceae & Nativa & 5 & $4 \%$ \\
\hline Ligustrum & Ligustrum lucidum W. T. Aiton & Oleaceae & Exótica & 3 & $3 \%$ \\
\hline $\begin{array}{l}\text { Não } \\
\text { identificada }\end{array}$ & 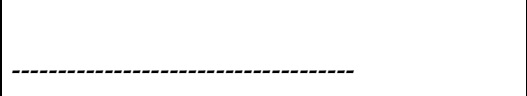 & |------------------ & |------- & 7 & $6 \%$ \\
\hline \multicolumn{4}{|l|}{ Total } & 116 & $100 \%$ \\
\hline Ausente & & & & 12 & \\
\hline
\end{tabular}




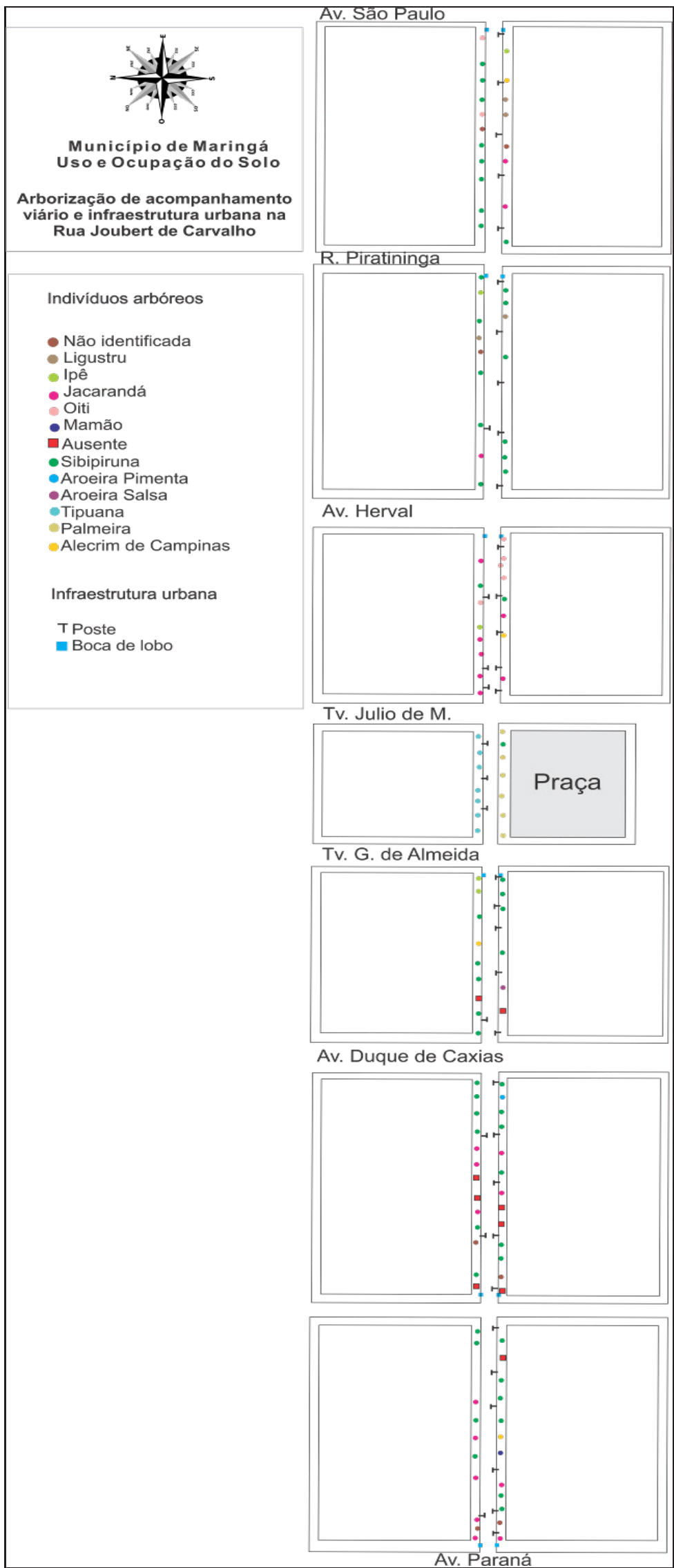

Figura 7 - Distribuição da arborização de acompanhamento viário e infraestrutura urbana na Rua Joubert de Carvalho, Maringá/PR. 
Os resultados do levantamento da arborização viária da Rua Joubert de Carvalho permitiram a identificação de 116 indivíduos arbóreos, dos quais 44\% são da espécie Sibipiruna (Poincianella pluviosa var. peltophoroides (Benth.) L. P. Queiroz) e 19\% da espécie Jacarandá (Jacaranda mimosifolia D. Don) ou seja, 63\% das árvores plantadas são concentradas em duas espécies. Foram identificados 13 espaços ausentes de árvores (Tabela 1).

O planejamento da arborização na cidade de Maringá contemplou espécies de grande porte e rápido crescimento, visando dar continuidade à mata ao redor da cidade. Assim, optou-se pelo predomínio de Sibipirunas (Poincianella pluviosa var. peltophoroides (Benth.) L. P. Queiroz.), flamboyants (Delonix regia (Boj ex. Hook) Rafin) e Jacarandás (Jacaranda mimosifolia D. Don). (DE ANGELIS et al., 2007).

Das espécies identificadas, 113 são de origem nativa e três de origem exótica, estas representadas pela Ligustrum (Ligustrum lucidum W. T. Aiton), que é reconhecida como espécie exótica invasora pela Portaria IAP n ${ }^{\circ} 074 / 2007$ (PARANÁ, 2007), portanto proibida por lei.

Identificou-se a presença de duas Palmeira Imperial (Roystonea oleracea (Jacq.) O. F. Cook) e cinco Côco (Cocos nucifera L.) no entorno de onde existia a antiga Estação Rodoviária de Maringá ${ }^{2}$.

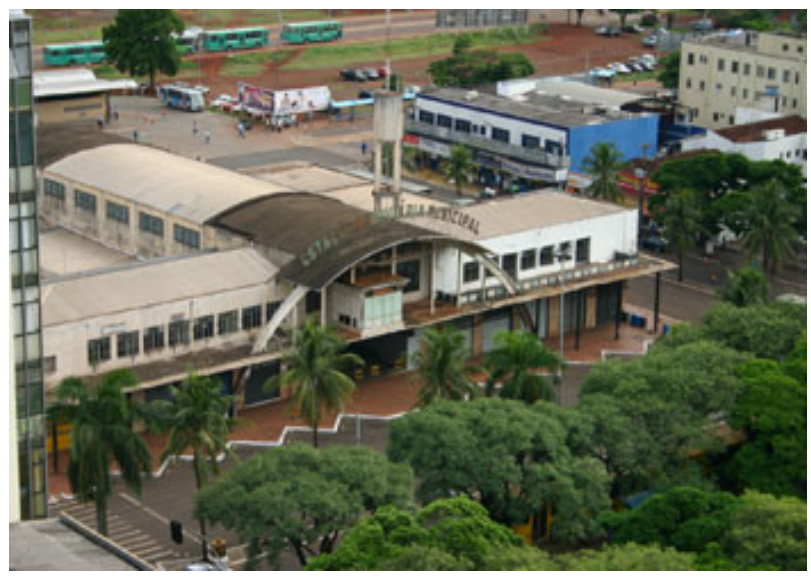

Figura 8 - Antiga Estação Rodoviária de Maringá, e presença de Palmeiras e Coco, ano de 2010 Fonte: Linjardi (2010)

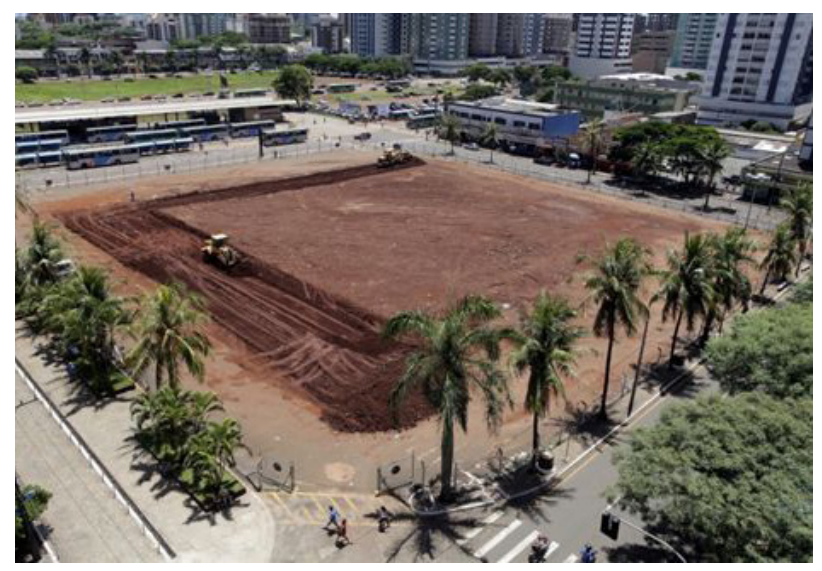

Figura 9 - Vista das Palmeiras e Coco e espaço livre onde existia a Estação Rodoviária de Maringá, demolida no ano de 2010.

Fonte: Pimenta (2011)

São espécies que fogem dos padrões de arborização visualizados ao longo da Rua. O plantio pode estar relacionado à antiga rodoviária, pois um alinhamento de um renque de Palmeiras e Côcos ressalta a perspectiva ou sugere a imponência aos espaços (MASCARÓ, 2002), conforme resgate fotográfico nas Figuras 8 e 9.

Quanto ao status (Tabela 2) dos indivíduos, observou-se que 74\% estão em estado regular, ou

Tabela 2 - Status dos indivíduos arbóreos estudados

\begin{tabular}{l|c|c}
\hline \multicolumn{1}{c|}{ Status } & $\begin{array}{c}\text { Indivíduos } \\
\text { arbóreos }\end{array}$ & $\mathbf{( \% )}$ \\
\hline Regular & 95 & 74,00 \\
\hline Jovem & 21 & 17,00 \\
\hline Morta & 0 & 0,00 \\
\hline Cortada & 0 & 0,00 \\
\hline Ausente & 12 & 9,00 \\
\hline Total & 128 & $100 \%$ \\
\hline
\end{tabular}

2 A Estação Rodoviária de Maringá foi demolida pela Prefeitura Municipal de Maringá no ano de 2010. 
seja, são árvores acima de $3 \mathrm{~m}$ de altura, com idade acima dos 10 anos; $17 \%$ são consideradas jovens, ou seja, são árvores abaixo de $3 \mathrm{~m}$ de altura, em geral, representadas por mudas. Observou-se que

Tabela 3 - Sistema radicular dos indivíduos arbóreos estudados*

\begin{tabular}{l|c|c}
\hline \multicolumn{1}{c|}{ Sistema radicular } & $\begin{array}{c}\text { Indivíduos } \\
\text { arbóreos }\end{array}$ & (\%) \\
\hline Sem afloramento & 107 & 92,00 \\
\hline $\begin{array}{l}\text { Com afloramento dentro } \\
\text { da área livre }\end{array}$ & 01 & 1,00 \\
\hline Afetando calçada ou via & 08 & 7,00 \\
\hline $\begin{array}{l}\text { Afetando rede } \\
\text { subterrânea }\end{array}$ & 0 & 0,00 \\
\hline Total & $\mathbf{1 1 6}$ & $100 \%$ \\
\hline
\end{tabular}

dentre as mudas há predominância do plantio de Oiti e Jacarandá.

Em relação ao sistema radicular (Tabela 3), o levantamento permitiu esclarecer que $92 \%$ das árvores não têm afloramento, e apenas $1 \%$ com afloramento dentro da área livre. As árvores que estão afetando calçadas ou vias correspondem a 7\% do total, representado pelas Sibipirunas.

*Aplicável apenas quando o status seja regular ou jovem

Tabela 4 - Características da rede elétrica dominante junto aos indivíduos arbóreos estudados

\begin{tabular}{l|c|c}
\hline Quando a rede elétrica & $\begin{array}{c}\text { Indivíduos } \\
\text { arbóreos }\end{array}$ & (\%) \\
\hline Rede compacta & 29 & 23,00 \\
\hline Rede elétrica simples & 00 & 0,00 \\
\hline Sem rede elétrica & 72 & 56,00 \\
\hline $\begin{array}{l}\text { Apenas baixa tensão } \\
\begin{array}{l}\text { Sem rede elétrica, porém } \\
\text { como poste (ligação } \\
\text { predial) }\end{array}\end{array}$ & 08 & 6,00 \\
\hline $\begin{array}{l}\text { Rede elétrica de alta } \\
\text { tensão não compacta }\end{array}$ & 18 & 14,00 \\
\hline \begin{tabular}{l} 
Total \\
\hline
\end{tabular}
\end{tabular}

Observou-se diversidade em relação às características da rede elétrica (Tabela 4), dos quais 23\% dos indivíduos arbóreos estão localizados sob domínio de rede compacta e $14 \%$ sob rede elétrica de 
alta tensão não compacta. Ademais, $56 \%$ dos indivíduos estão localizados em locais onde não existe rede elétrica de alta ou baixa tensão.

As características da rede elétrica dominante, no qual há predomínio de locais sem rede elétrica e sob rede compacta, são fatores que explicam os resultados do levantamento quanto ao item "podas anteriores" (Tabela 5), no qual foram identificados que 83\% das árvores não há indícios de poda anterior.

Tabela 5 - Podas anteriores dos indivíduos arbóreos estudados

\begin{tabular}{l|c|c}
\hline $\begin{array}{c}\text { Quando as podas } \\
\text { anteriores }\end{array}$ & $\begin{array}{c}\text { Indivíduos } \\
\text { arbóreos }\end{array}$ & (\%) \\
\hline Poda elétrica & 14 & 12,00 \\
\hline Poda edificação & 02 & 2,00 \\
\hline Sem poda anterior & 96 & 83,00 \\
\hline Com poda drástica & 04 & 3,00 \\
\hline Total & $\mathbf{1 1 6}$ & $100.00 \%$ \\
\hline
\end{tabular}

Observou-se que nos locais onde tem rede elétrica de alta tensão não compacta ou apenas de baixa tensão é que ocorreram os maiores índices de poda drástica. Com este dado, pode-se inferir que o maior responsável pela poda drástica seja a empresa responsável pelo sistema de distribuição de energia elétrica.

De acordo com Milano e Dalcin (2000), as redes compactas permitem uma relação menos conflitiva e mais segura com os indivíduos arbóreos, pois são constituídas por cabos protegidos e isolados, dispostos de forma concentrada. Foram implantadas em Maringá de forma pioneira pela Companhia Paranaense de Energia (COPEL).

Velasco (2003) destaca que a utilização de redes compactas de distribuição de energia elétrica é praticamente o mesmo valor de custo da rede tradicional. No caso da implantação da rede compacta, os resultados para os indivíduos arbóreos e para ambiência urbana são positivos, pois há uma melhora no aspecto geral das árvores e logradouros, menor porcentagem de podas e redução de 79,5\% nos custos de manutenção das árvores quando comparado com a rede tradicional.

Segundo Milano e Dalcin (2000), árvores de grande porte podem ser utilizadas sob redes, com restritos problemas e baixas demandas de podas. O plantio de árvores de grande porte sob a rede elétrica é possível, desde que a muda não seja plantada no alinhamento da rede e que a copa das árvores seja conduzida precocemente por meio do trato silvicultural adequado, acima dessa rede. A Prefeitura Municipal de São Paulo permite o plantio de espécies de grande porte sob redes elétricas desde que a calçada apresente largura superior a 3m (SÃO PAULO, 2005), ou seja, há uma preocupação com os conflitos que podem ser causados entre os equipamentos de infraestrutura, as árvores e a questão de acessibilidade.

A solução mais adotada para o problema da proximidade de espécies com a rede elétrica é a poda. Porém, esta geralmente compromete a sanidade das árvores pelo fato de, na maioria das vezes, ser drástica (MASCARÓ, 2002).

Em relação ao conflito com a infraestrutura urbana, observou-se que $66 \%$ das árvores não causam conflitos (Tabela 6).

Apesar de $66 \%$ dos indivíduos arbóreos não estarem associado aos conflitos com infraestrutura urbana, os demais $34 \%$ tem qualidade comprometida devido as ocorrências de conflitos. Tal fato é resultado do planejamento e gestão inadequada decorrente das ações do poder público municipal, que executa o plantio de espécies de grande porte (Jacarandás) sob rede de fiação elétrica, distância mínima insuficiente de postes, edificações e bocas de lobo.

São Paulo (2005) determina que a distância mínima das árvores com os postes seja de $3 \mathrm{~m}$ para 
Tabela 6 - Quanto ao conflito com a infraestrutura urbana

\begin{tabular}{l|c|c}
\multicolumn{1}{c|}{ Quanto ao conflito } & $\begin{array}{c}\text { Indivíduos } \\
\text { arbóreos }\end{array}$ & (\%) \\
\hline Conflito com edificação & 9 & 8,00 \\
\hline Conflito com poste & 7 & 6,00 \\
\hline Conflito com bocas de lobo & 1 & 1,00 \\
\hline Conflito com pedestres & 0 & 0,00 \\
\hline Conflito com veículos & 0 & 0,00 \\
\hline Conflito com fiação & 13 & 11,00 \\
\hline Conflito com edificação e fiação & 4 & 3,00 \\
\hline Conflito com poste e fiação & 1 & 1,00 \\
\hline $\begin{array}{l}\text { Conflito com poste e bocas de } \\
\text { lobo }\end{array}$ & 1 & 1,00 \\
\hline $\begin{array}{l}\text { Conflito com edificação, poste e } \\
\text { fiação }\end{array}$ & 1 & 1,00 \\
\hline Conflito com edificação e poste & 2 & 2,00 \\
\hline Não causa conflito & $\mathbf{1 3 0}$ & 66,00 \\
\hline Total & $100.00 \%$ \\
\hline
\end{tabular}

espécies de pequeno porte, $4 \mathrm{~m}$ para as de médio porte e $5 \mathrm{~m}$ para as de grande porte. Para Porto Alegre (2006), a distância mínima é de $2 \mathrm{~m}$. Na Rua Joubert de Carvalho foram diagnosticadas distâncias mínimas de apenas $0,75 \mathrm{~m}$ (Figura 10).

As distâncias mínimas para as caixas de inspeção (boca de lobo, poço de visita, caixas de passagem) são de $2 \mathrm{~m}$ para espécies de pequeno e médio porte e de $3 \mathrm{~m}$ para as de grande porte (SÃO PAULO, 2005). Para Porto Alegre (2006), a distância deve ser de 1,25 m. Na Rua Joubert de Carvalho foram diagnosticadas distâncias mínimas de $0,30 \mathrm{~m}$ (Figura 11).

Nos locais onde existe recuo das edificações a partir do alinhamento predial, houve um desenvolvimento qualitativo das árvores, representado pelas copas frondosas (Figura 12). Por outro lado, nos locais onde há avanço das edificações a partir do alinhamento predial, há conflitos que desencadeiam as podas drásticas (Figura 13).

A copa frondosa é resultado do planejamento adequado de todas as partes da árvore, seja subsolo, solo e aérea, como: transplante, plantio, tutoramento, poda adequada e presença de área livre permeável. É reflexo direto da distância adequada dos equipamentos dos sistemas de infraestrutura urbana e edificações.

A escolha das espécies para a implantação no acompanhamento viário está condicionada por muitos fatores, dentre os quais o uso e ocupação do solo (porte dos edifícios, recuos, afastamentos, marquises) e os desempenhos paisagísticos e ambientais urbanos que se deseja obter.

Os principais fatores que comprometem a saúde das árvores urbanas são a compactação e a contaminação do solo, podas drásticas, pequena diversidade de espécies, depredação, estresse hídrico, temperaturas extremas e iluminação noturna (MENEGHETTI, 2003). 


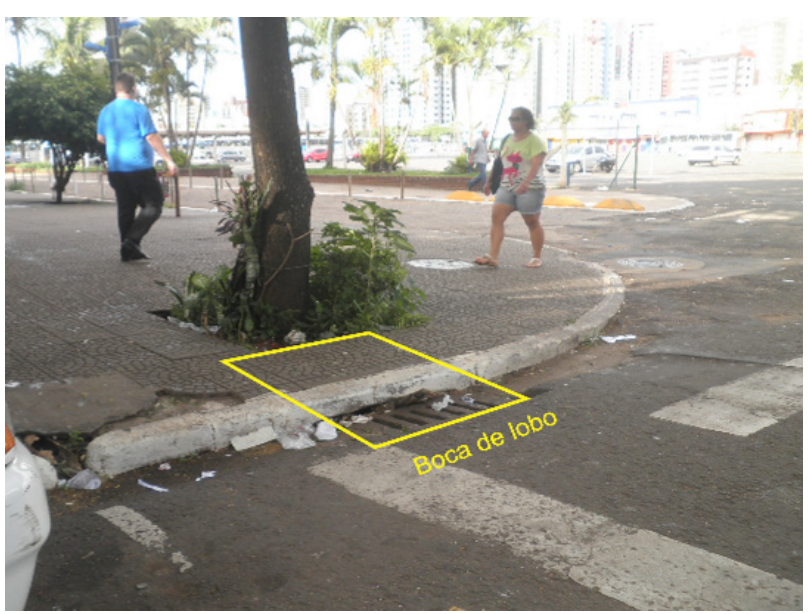

Figura 10 - Conflito da árvore com boca de lobo na Rua Joubert de Carvalho, próximo ao extinto terminal rodoviário.

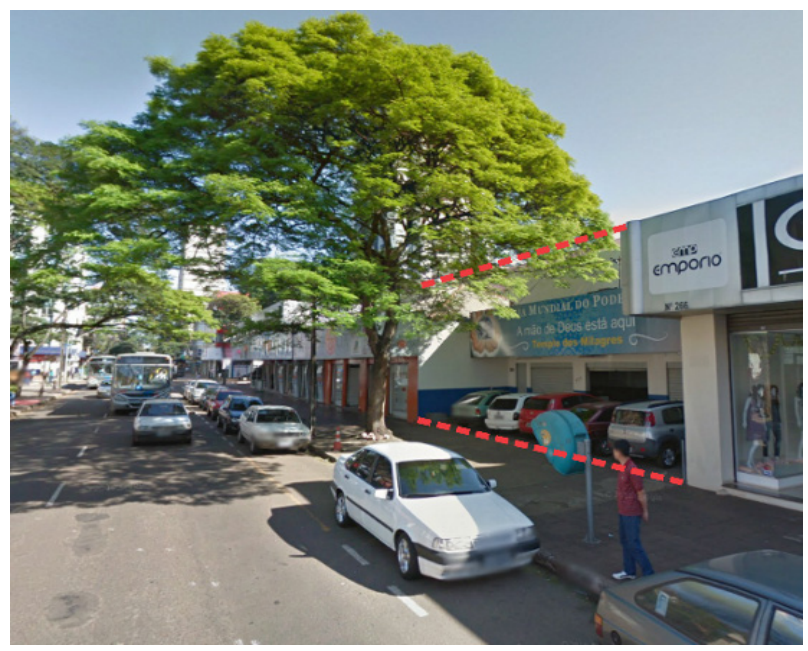

Figura 12 - Recuo da edificação e copa frondosa da espécie Sibipiruna na Rua Joubert de Carvalho.

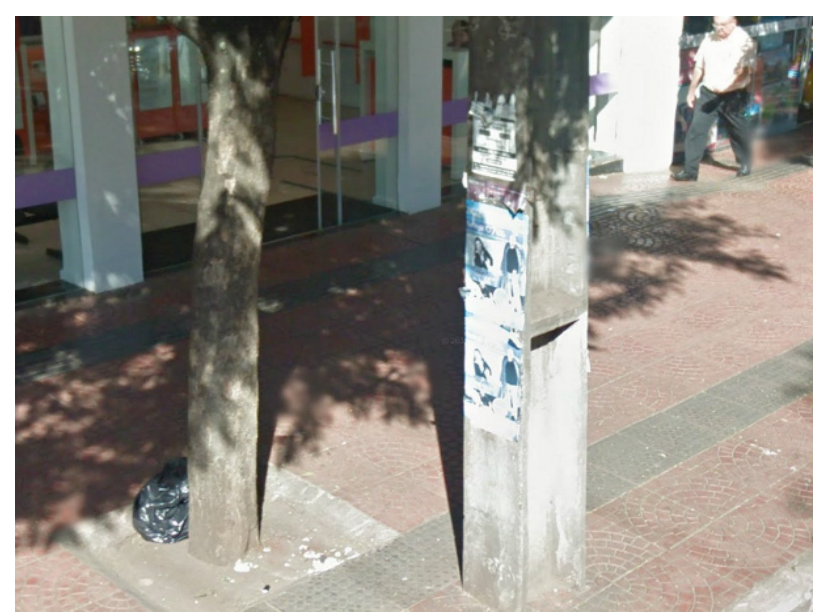

Figura 11 - Conflito da árvore com poste na Rua Joubert de Carvalho, esquina com Av. Duque de Caxias.

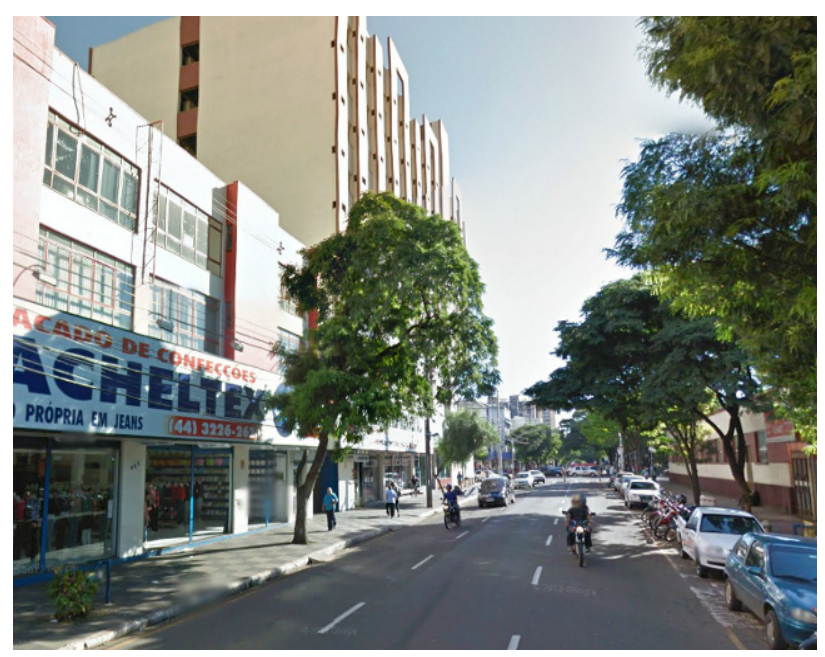

Figura 13 - Poda drástica devido ao conflito da árvore com a edificação na Rua Joubert de Carvalho.

Em que pese a exuberância da arborização de acompanhamento viário em Maringá, e seus incontáveis benefícios, é visível o descaso do poder público nas últimas décadas. Os problemas multiplicam-se a uma velocidade superior à capacidade de serem sanados ou evitados. Essa inépcia decorre, sobretudo, pela não existência de um plano municipal de arborização e pela carência extremada de mão-de-obra em número suficiente para atender as demandas do setor (SAMPAIO, 2006).

\section{CONCLUSÃO}

O presente estudo conclui que na Rua Joubert de Carvalho foram identificados 116 indivíduos arbóreos, dos quais $44 \%$ são da espécie Sibipiruna (Poincianella pluviosa var. peltophoroides (Benth.) L. P. Queiroz) e 19\% da espécie Jacarandá (Jacaranda mimosifolia D. Don) ou seja, 63\% das árvores plantadas são concentradas em duas espécies; $74 \%$ estão em estado regular, ou seja, são árvores acima de $3 \mathrm{~m}$ de altura com idade acima dos 10 anos.

Em relação ao sistema radicular $92 \%$ das árvores não têm afloramento, e apenas 1\% com aflo- 
ramento dentro da área livre. As árvores que estão afetando calçadas ou vias correspondem a 7\% do total, representados em $100 \%$ dos casos por Sibipirunas.

Quanto à poda, conclui-se que em $83 \%$ dos indivíduos não houve indícios de "poda anterior", entretanto, foram identificadas poda elétrica, poda edificação e podas drásticas.

Observou-se diversidade em relação às características da rede elétrica, dos quais $23 \%$ dos indivíduos arbóreos estão localizados sob domínio de rede compacta, $14 \%$ sob rede elétrica de alta tensão não compacta, $6 \%$ apenas baixa tensão, $1 \%$ sem rede elétrica, porém com ligação predial, e $56 \%$ dos indivíduos estão localizados em locais onde não existe rede elétrica de alta ou baixa tensão.

O conflito entre árvore e infraestrutura urbana (calçadas, bocas de lobo, postes e energia elétrica) permitiu concluir que $66 \%$ das árvores não causam conflitos. Porém, os demais $34 \%$ tem qualidade comprometida devido as ocorrências de conflitos.

\section{REFERÊNCIAS}

APG II. An update of the Angiosperm Phylogeny Group classification for the orders and families of flowering plants: APG II. BotanicalJournaloftheLinneanSociety141: 399 - 436, 2003.

BARROS, R. A. Arborização viária urbana e o seu potencial turístico na cidade de Maringá/PR. Dissertação (Mestrado) Universidade Estadual de Maringá, 2010. Disponível em: <http://www.peu.uem.br/Discertacoes/ Rafaela.pdf> Acesso em: 15/06/2013.

CARVALHO, J. P.F. A árvore no Espaço Urbano. Universidade de Trás-os-Montes e Alto Douro, Dep. Ciências Florestais e Arquitetura. IV Jornadas do Ambiente. 19 de junho, 2009. C.M. Vila Pouca de Aguiar. Disponível em:<http://www.cmvpaguiar.pt/files/2/documentos/20090709173625125029.pdf> Acesso em: $15 / 06 / 2013$.

COPEL. Guia de Arborização em Vias Públicas. Curitiba, 2008.

DE ANGELIS, B. L. D.; SAMPAIO, A. C. F.; TUDINI, O. G.; ASSUNCAO, M. G. T.; DE ANGELIS NETO, G. Avaliação das árvores de vias públicas da zona central de Maringá, Estado do Paraná: estimativa de produção de resíduos e destinação final. Acta Scientiarum. Agronomy, v. 29, p. 133-140, 2007.

IBGE - Instituto Brasileiro de Geografia e Estatística. Cidades, 2013. Disponível em <http://www.cidades. ibge.gov.br/xtras/home.php>. Acesso em: 28 jan 2014.

INSTITUTO DE TERRAS, CARTOGRAFIA E GEOCIÊNCIAS (ITCG). Produtos cartográficos. Dados e informações geoespaciais temáticos. Curitiba, 2007.

HISTÓRIA de Maringá. O Diário do Norte do Paraná. Maringá, 2010. Disponível em: < http://www.odiario. com/historiademaringa/>. Acesso em: 28 jan. 2014.

LINJARDI, F. Prefeitura deposita R \$ 9,6 milhões e ganha posse da antiga rodoviária. O Diário do Norte do Paraná, Maringá, 10 maio. 2010. Disponível em: < http://blogs.odiario.com/linjardi/2010/05/10/prefeitura-deposita-r-96-mi-e-ganha-posse-da-rodoviaria/>. Acesso em: 28 jan. 2014.

MARINGÁ. Lei 110 de 25 de Outubro de 1958. Autorizar denomina "Rua Joubert de Carvalho" a atual Rua Bandeirantes. Prefeitura Municipal de Maringá, Maringá, PR, 6 nov. 1958.

Lei complementar $n^{\circ} 888 / 2011$. Substitui a Lei complementar $n^{\circ} 331 / 1999$, que dispõe sobre o uso e ocupação do solo no município de Maringá e dá outras providências. Maringá, 2011.

MASCARÓ, J. L. Manual de loteamentos e urbanizações. Porto Alegre: Sagra/ DCLuzzatto, 1994.

MASCARÓ, Lucia Elvira Alicia Raff; MARCARÓ, Juan Luis. Vegetação urbana. Porto Alegre: UFRS, 2002. 
242p.

MENEGHETTI, G. I. P. Estudo de dois métodos de amostragem para inventário da arborização de ruas dos bairros da orla marítima do município de Santos/SP. Dissertação (Mestrado), Escola Superior de Agricultura Luiz de Queiroz, Universidade de São Paulo, 2003.

MILANO, M.S; DALCIN, E. Arborização de vias públicas. Rio de Janeiro: Light, 2000. 226p.

PARANÁ. PortariaIAP n074, de 19 de Abril de 2007. Reconhece a ListaOficial de EspéciesExóticasInvasoras para o Estado do Paraná, estabelecenormas de controle e dáoutrasprovidências. InstitutoAmbiental do Paraná, Curitiba, PR, 19 abr. 2007.

PIMENTA, R. Terreno da antiga rodoviária de Maringá deve virar estacionamento em 10 dias.O Diário do Norte do Paraná, Maringá, 24 Jan. 2011. Disponível em: <http://maringa.odiario.com/maringa/noticia/386551/terreno-da-antiga-rodoviaria-deve-virar->. Acesso em: 28 jan. 2014.AAAAAo-em-10-dias.html

PORTO ALEGRE. ResoluçãoComan n 05 de 28 de Setembro de 2006. Dispõesobre o Plano Diretor de Arborização Urbana de Porto Alegre. Conselho Municipal do MeioAmbiente (coman), PortoAlegre, RS, 28 set. 2006.

ROLNIK, Raquel. O que é cidade. 4ed. São Paulo: Brasiliense, 1956.

REGO, R. L. O desenho urbano de Maringá e a ideia de cidade-jardim. Acta Scientiarum. Maringá, v. 23, n. 6, p. 1569-1577, 2001.

SAMPAIO, A. C. F. Análise da arborização de vias públicas da área piloto de Maringá. 116p. Dissertação (Mestrado em Geografia). Universidade Estadual de Maringá, Maringá, 2006.

SÃO PAULO. Secretaria do verde e do meio ambiente. Manual técnico de arborização urbana. São Paulo, 2005, 45p. Disponível em: <http://www.prefeitura.sp.gov.br/cidade/secretarias/upload/manual arborizacao 1253202256.pdf $>$. Acesso em 31 Jan 2014.

SOUZA, V. C.; LORENZI, H. Botânica sistemática: guia ilustrado para identificação das famílias de Angiospermas da flora brasileira, baseado em APG II. 2 ed. Nova Odessa, SP: Instituto Plantarum, 2008.

VELASCO. G. N. Arborização viária x sistemas de distribuição de energia elétrica: avaliação dos custos, estudo das podas e levantamento de problemas fitotécnicos. Piracicaba, 2003. 94p. Dissertação (Mestrado) Escola Superior de Agricultura "Luiz de Queiroz", Universidade de São Paulo.

ZMITROWICZ, Witold; DE ANGELIS NETO, Generoso. Infraestrutura urbana. Texto Técnico da Escola Politécnica da USP. Universidade de São Paulo, Departamento de Construção Civil, São Paulo, 1997. 